\title{
BMJ Open Study protocol for an open-label, single- arm, multicentre phase II trial to evaluate the efficacy and safety of combined triplet therapy and olanzapine for prevention of carboplatin-induced nausea and vomiting in gynaecological cancer patients
}

Hirotoshi lihara, ${ }^{1,2}$ Mototsugu Shimokawa, ${ }^{3}$ Masakazu Abe, ${ }^{4}$ Yoh Hayasaki, ${ }^{5}$ Yukiyoshi Fujita, ${ }^{6}$ Yuki Nagasawa, ${ }^{6}$ Michiru Sakurai, ${ }^{7}$ Rie Matsuoka, ${ }_{1}^{1}$ Akio Suzuki, ${ }^{1}$ Kenichiro Morishige ${ }^{5}$

To cite: lihara H, Shimokawa M, Abe M, et al. Study protocol for an open-label, single-arm, multicentre phase II trial to evaluate the efficacy and safety of combined triplet therapy and olanzapine for prevention of carboplatin-induced nausea and vomiting in gynaecological cancer patients. BMJ Open 2019;9:e024357. doi:10.1136/ bmjopen-2018-024357

- Prepublication history for this paper is available online. To view these files, please visit the journal online (http://dx.doi. org/10.1136/bmjopen-2018024357).

Received 23 May 2018 Accepted 19 November 2018

Check for updates

(C) Author(s) (or their employer(s)) 2019. Re-use permitted under CC BY-NC. No commercial re-use. See rights and permissions. Published by BMJ.

For numbered affiliations see end of article.

Correspondence to Dr Hirotoshi lihara; dai0920@gifu-u.ac.jp

\section{ABSTRACT}

Introduction Carboplatin (CBDCA) administered at a dosage of $4 \mathrm{mg} / \mathrm{mL} / \mathrm{min}$ or more area under the blood concentration-time curve (AUC) is considered to be ranked as the highest chemotherapy-induced nausea and vomiting (CINV) risk of the moderately emetogenic chemotherapy agents. The complete response (CR) rate for preventing overall CINV, defined as no emetic episodes and no use of rescue medication, for standard triplet antiemetic therapy (5- $\mathrm{HT}_{3} \mathrm{RA}, 5$-hydroxytryptamine-3 receptor antagonist; $\mathrm{NK}_{1} \mathrm{RA}$, neurokinin-1 receptor antagonist; DEX, dexamethasone) was approximately $60 \%$ in gynaecological cancer patients receiving CBDCAbased therapy. Further improvement in antiemetic treatment is needed to optimise care. This trial is to evaluate the efficacy and safety of using $5 \mathrm{mg}$ olanzapine (OLZ) plus standard triplet antiemetic therapy for CINV after $\mathrm{AUC} \geq 4 \mathrm{mg} / \mathrm{mL} / \mathrm{min}$ CBDCA combination therapy in gynaecological cancer patients.

Methods and analysis This trial is an open-label, singlearm, multicentre phase II trial. Patients who receive CBDCA (AUC $\geq 4$ )-based therapy and have never been administered moderate to high emetogenic chemotherapy will be enrolled. All patients will receive OLZ ( $5 \mathrm{mg}$ oral administration on days 1-4, after supper) in combination with $5-\mathrm{HT}_{3} \mathrm{RA}, \mathrm{NK}_{1} \mathrm{RA}$ and DEX. The primary endpoint is the $\mathrm{CR}$ rate during the overall period (0-120 hours). Testing the hypothesis that this regimen can improve $\mathrm{CR}$ rate from $60 \%$ (null hypothesis) to $75 \%$ (alternative hypothesis) with a one-sided type I error of 0.1 and power of 0.8 will require 53 patients. Considering the dropout rate, the target sample size is set at 60 .

Ethics and dissemination The study protocol was approved by the institutional review board at each of the participating centres. Data will be presented at international conferences and published in peer-reviewed journals.

Trial registration number UMIN000031646.

\section{Strengths and limitations of this study}

- This is a first trial to evaluate efficacy and safety of combination of using $5 \mathrm{mg}$ olanzapine (OLZ) plus standard triplet antiemetic therapy for chemotherapy-induced nausea and vomiting after area under the blood concentration-time curve $\geq 4 \mathrm{mg} / \mathrm{mL} / \mathrm{min}$ carboplatin combination therapy in gynaecological cancer patients.

- The data will be used to inform a future large multicentre double-blind randomised phase III trial comparing $5 \mathrm{mg}$ of OLZ combination therapy to conventional triplet antiemetic therapy.

Limitations are open-label and single-arm design.

\section{INTRODUCTION}

Chemotherapy-induced nausea and vomiting (CINV) lowers patients' quality of life and reduces adherence to treatment; in the worst case, it can affect the treatment effect and curability. CINV frequently occurs after treatment with anticancer agents and patients report it to be the most distressing adverse event during treatment. ${ }^{1}$ In the American Society of Clinical Oncology ${ }^{2}$ and Multinational Association of Supportive Care in Cancer (MASCC)/European Society for Medical Oncology (ESMO), ${ }^{3}$ carboplatin (CBDCA) administered at a dosage of a $4 \mathrm{mg} / \mathrm{mL} / \mathrm{min}$ or more area under the blood concentration-time curve (AUC) is reclassified to be ranked as highest CINV risk of the moderately emetogenic chemotherapy. Furthermore, National Comprehensive Cancer Network, ${ }^{4}$ CBDCA at an AUC of $4 \mathrm{mg} / \mathrm{mL} / \mathrm{min}$ or more was escalated to the highly emetogenic chemotherapy (HEC) 
classification. And all guidelines recommend a three-drug combination therapy of 5-hydroxytryptamine-3 receptor antagonist (5-HT $\left.{ }_{3} \mathrm{RA}\right)$, dexamethasone (DEX) and neurokinin-1 receptor antagonist $\left(\mathrm{NK}_{1} \mathrm{RA}\right)$ as antiemetic prophylaxis. However, in a randomised phase III trials of female patients or patients with gynaecological cancer receiving CBDCA, the complete response (CR) rates for this standard antiemetic triplet therapy $\left(5-\mathrm{HT}_{3} \mathrm{RA}\right.$, $\mathrm{NK}_{1} \mathrm{RA}$ and DEX) were $62 \%{ }^{5}$ and $61.6 \%,{ }^{6}$ respectively. It is quite different from the CR rates reported in lung cancer patients (Ito et al $80.3 \%,{ }^{7}$ Kusagawa et al $80.5 \%{ }^{8}$ ). This difference is due to the background of cancer types. Female sex and younger age are well-known risk factors. ${ }^{9-12}$ Given the insufficiency of these control rates, further improvement in antiemetic treatment is urgently needed, particularly for these sub-groups.

Olanzapine (OLZ) is classified as a multi-acting receptor-targeted antipsychotic that blocks dopaminergic $\mathrm{D}_{1}$, $\mathrm{D}_{2}, \mathrm{D}_{3}$ and $\mathrm{D}_{4}$ receptors, serotonergic $5-\mathrm{TH}_{2 \mathrm{~A}}, 5-\mathrm{HT}_{2 \mathrm{~B}}$, $5-\mathrm{HT}_{3}$ and $5-\mathrm{HT}_{6}$ receptors, histamine $\mathrm{H}_{1}$ receptors and muscarinic acetylcholine receptors $\mathrm{M}_{1}, \mathrm{M}_{2}, \mathrm{M}_{3}$ and $\mathrm{M}_{4} \cdot{ }^{13}$ Based on these known effects, OLZ is expected to improve CINV.

A study by Navari et al revealed the efficacy and safety of the combination of $10 \mathrm{mg}$ OLZ and standard antiemetic triplet therapy in HEC, which included anthracycline/cyclophosphamide and cisplatin in a randomised, double-blind phase III trial. ${ }^{14}$ The CR rates in the overall phase were reported as $40.6 \%$ (three-drugs) versus $63.6 \%$ (four-drugs), however, the patient sedation due to the OLZ has been concerned. It is reported that females are prone to increased blood concentrations of OLZ than male. ${ }^{15}$ Because of this reason, there is concern about the enhancement of effect and side effect of OLZ in females.

Three phase II studies have revealed the efficacy and safety of the combination of $5 \mathrm{mg}$ OLZ and standard antiemetic triplet therapy for CINV induced by HEC in Japan. ${ }^{16-18}$ Furthermore, a study by Yanai et al reported that $5 \mathrm{mg}$ OLZ and $10 \mathrm{mg}$ OLZ have a comparable effect, with $5 \mathrm{mg}$ OLZ also having a lower sedative effect. ${ }^{18}$

Based on these preliminary studies, we planned an open-label, single-arm, multicentre phase II trial to evaluate the efficacy and safety of using $5 \mathrm{mg}$ OLZ plus granisetron (GRA), NK $\mathrm{NA}_{1}$ and DEX for the prevention of nausea and vomiting after AUC $\geq 4 \mathrm{mg} / \mathrm{mL} /$ min CBDCA combination therapy in gynaecological cancer patients.

\section{STUDY PROTOCOL \\ Objective}

The objective of this study is to investigate the efficacy and safety of using $5 \mathrm{mg}$ OLZ plus GRA, NK, RA (aprepitant (APR) or fosaprepitant) and DEX to prevent nausea and vomiting after AUC $\geq 4 \mathrm{mg} / \mathrm{mL} / \mathrm{min}$ CBDCA combination therapy in gynaecological cancer patients. The study protocol was approved by the institutional review board at each of the participating centres and was independently monitored by the alliance data centre and safety monitoring board.

\section{Study setting}

This study is an open-label, single-arm, multicentre phase II trial performed at three centres in Japan.

\section{End-points}

The primary end-point is the CR rate, defined as no emetic episodes and no use of rescue medication during the overall assessment period (0-120 hours post-CBDCA). The secondary end-points are: CR rate during the acute assessment period (0-24 hour); CR rate during two delayed assessment periods (24-120 hours and 24-168 hours); CR rate during the overall assessment period (0-168 hours) and the complete control rate, defined as no emetic episodes, no rescue medication use, and no significant nausea in the acute, delayed, and overall assessment periods. Significant nausea is defined as equal to or greater than 'moderate' on a four-grade categorical scale (none, mild, moderate, or severe). The total control rate is defined as no emetic episodes, no rescue medication use, and no nausea in the acute, delayed, and overall assessment periods. The levels of nausea, anorexia, sleepiness, impact on life severity and patient satisfaction with antiemetic therapy are also classified using a four-grade categorical scale. Adverse events are graded according to PRO-CTCAE V.1.0 and CTCAE V.4.0.

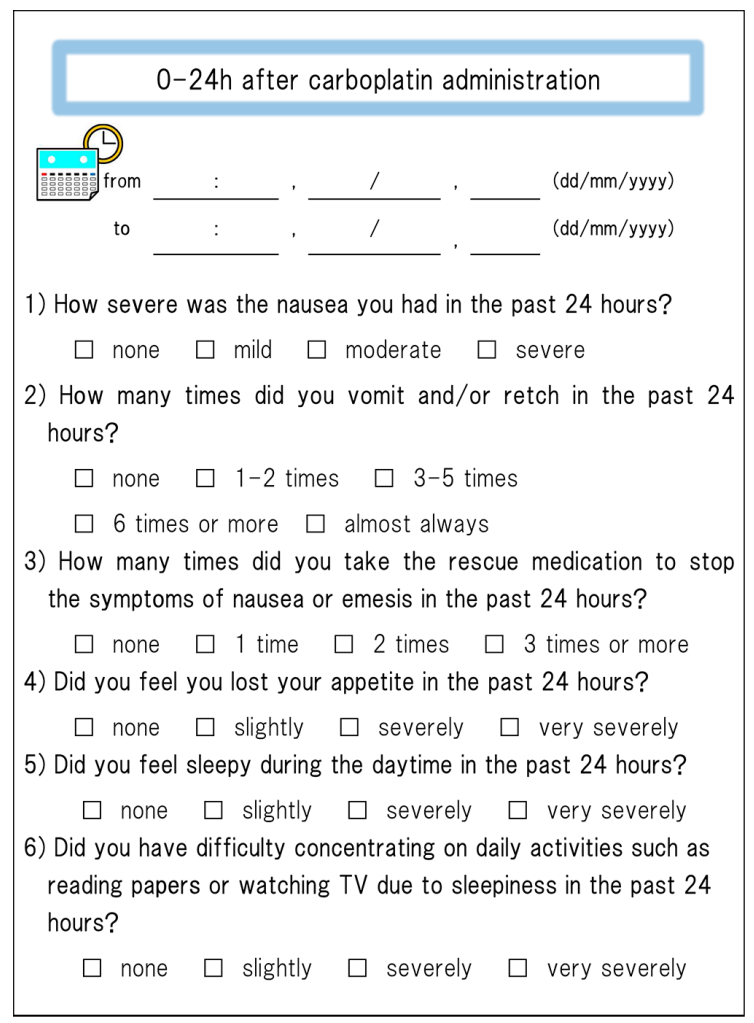

Figure 1 Patient-reported study diaries. 


\section{Date collection}

The data are collected from patient diaries (figure 1). Patients are required to fill the diary for every 24 hours from the start of chemotherapy to 168 hours periods. PRO-CTCAE is assessed before initiation of the treatment and 168 hours after the start of chemotherapy.

\section{Eligibility criteria}

\section{Inclusion criteria}

Patients included in the clinical trial must meet all of the following criteria:

i. Diagnosis of gynaecological cancer and scheduled to receive $\mathrm{CBDCA}-$ based chemotherapy ( $\mathrm{AUC} \geq 4$ ).

ii. Aged 20-79 years at time of enrolment.

iii. Eastern Cooperative Oncology Group performance status of 0,1 , or 2 .

iv. Absence of symptomatic brain metastasis and carcinomatosis.

v. No history of administration of moderate-to-high emetogenic chemotherapy drugs.

vi. No current use of any drug with antiemetic or somnolent activity, including 5- $\mathrm{HT}_{3} \mathrm{RA}, \mathrm{NK}_{1} \mathrm{RA}$, corticosteroids, dopamine receptor antagonists, phenothiazine tranquillisers, antihistamine drugs (paclitaxel administration allowed during premedication) and benzodiazepine agents.

vii. Within the following standard ranges for general clinical tests:

a. Aspartate aminotransferase $\leq 100 \mathrm{U} / \mathrm{L}$.

b. Alanine aminotransferase $\leq 100 \mathrm{U} / \mathrm{L}$.

c. Total bilirubin $\leq 2.0 \mathrm{mg} / \mathrm{dL}$.

viii. Provided written informed consent.

\section{Exclusion criteria}

Patients who meet any of the following criteria will be excluded from the trial:

i. History of hypersensitivity or allergy to study drugs or similar compounds.

ii. Need for antiemetics at the time of enrolment.

iii. Started opioid intake within 48 hours prior to enrolment.

iv. Presence of unstable angina, ischaemic heart disease, cerebral haemorrhage or apoplexy, or active gastric or duodenal ulcer within 6 months prior to enrolment.

v. Presence of convulsive disorders requiring anticonvulsant therapy.

vi. Presence of ascites effusion requiring paracentesis.

vii. Presence of gastrointestinal obstruction.

viii. Breastfeeding or pregnant women or those not willing to use contraception.

ix. Presence of psychosis or psychiatric symptoms that interfere with daily life.

x. Abdominal or pelvic irradiation within 6 days prior to enrolment.

xi. Presence of diabetes mellitus.

xii. Being a habitual smoker at the time of enrolment.

xiii. Patients deemed inappropriate for the study by the investigator.
Table 1 Antiemetic administrations

\begin{tabular}{|c|c|c|c|c|c|}
\hline \multicolumn{2}{|l|}{ Antiemetics } & \multirow{2}{*}{$\frac{\text { Day } 1}{1 \mathrm{mg}}$} & \multirow[t]{2}{*}{ Day 2} & \multirow[t]{2}{*}{ Day 3} & \multirow[t]{2}{*}{ Day 4} \\
\hline Granisetron & IV & & & & \\
\hline \multirow{2}{*}{$\begin{array}{l}\text { Aprepitant or } \\
\text { fosaprepitant }\end{array}$} & $\mathrm{PO}$ & $125 \mathrm{mg}$ & $80 \mathrm{mg}$ & $80 \mathrm{mg}$ & \\
\hline & IV & $150 \mathrm{mg}$ & & & \\
\hline \multirow[t]{2}{*}{ Dexamethasone } & PO or & $12 \mathrm{mg}^{*}$ & & & \\
\hline & IV & $9.9 \mathrm{mg}^{*}$ & & & \\
\hline Olanzapine & $\mathrm{PO}$ & $5 \mathrm{mg}$ & $5 \mathrm{mg}$ & $5 \mathrm{mg}$ & $5 \mathrm{mg}$ \\
\hline
\end{tabular}

IV, intravenous infusion; PO, per os.

*When more than $135 \mathrm{mg} / \mathrm{m}^{2}$ of paclitaxel is used, on day $1 \mathrm{DEX}$ is

administered $19.8 \mathrm{mg}$ intravenously or $20 \mathrm{mg}$ orally.

\section{Registration}

Patient registration started in April 2018.

\section{Treatment methods}

The study antiemetics administrations are shown in table 1. All patients receive GRA ( $1 \mathrm{mg}$ intravenous infusion on day 1 , $30 \mathrm{~min}$ before chemotherapy), APR (125 mg oral administration on day 1, 1 hour before chemotherapy and $80 \mathrm{mg}$ in the morning on days 2 and 3), DEX (9.9 mg intravenous infusion or $12 \mathrm{mg}$ oral administration on day 1, $30 \mathrm{~min}$ before chemotherapy) and OLZ (5mg oral administration on days 1-4, after supper). In cases where fosaprepitant (150 mg intravenous infusion, 1 hour before chemotherapy) is used instead of APR on day 1 , no additional APR is administered on days 2-3. In addition, when more than $135 \mathrm{mg} / \mathrm{m}^{2}$ of paclitaxel is used, on day $1 \mathrm{DEX}$ is administered $19.8 \mathrm{mg}$ intravenously or $20 \mathrm{mg}$ orally.

\section{Follow-up}

Physical and blood examinations are scheduled for each patient before initiation of the treatment and daily from days 5-15. The study diaries are collected from

\begin{tabular}{|c|c|c|c|c|c|c|c|c|c|c|}
\hline & Eurolment & Eurolnent & \multicolumn{8}{|c|}{ Post-enrolment } \\
\hline TIMEPONT & -8 days & 0 & $d a y$ & $\frac{d a y}{2}$ & day & $d a y$ & $d a y$ & $\begin{array}{c}d a y \\
6 \\
6\end{array}$ & $\frac{d a y}{y}$ & $d a y$ \\
\hline ENROLMENT: & & & & & & & & & & \\
\hline Eligibility screen & $\mathrm{x}$ & & & & & & & & & \\
\hline History and physical & $\mathrm{x}$ & & & & & & & & & \\
\hline ECOG PS & $\mathrm{x}$ & & & & & & & & & \\
\hline Laboratory studies & $\mathrm{x}$ & & & & & & & $\mathrm{x}$ & & \\
\hline Informed consent & $\mathrm{x}$ & & & & & & & & & \\
\hline Enrolment & & $\mathrm{x}$ & & & & & & & & \\
\hline INTERVENTIONS: & & & & & & & & & & \\
\hline $\begin{array}{c}\text { Antiemetic } \\
\text { administrations }\end{array}$ & & & $\curvearrowleft$ & & & $\rightarrow$ & & & & \\
\hline ASSESSMENTS: & & & & & & & & & & \\
\hline Pattient dituries & & $\mathrm{x}$ & $\mathrm{x}$ & $\mathrm{x}$ & $\mathrm{x}$ & $\mathrm{x}$ & $\mathrm{x}$ & $\mathrm{x}$ & $\mathrm{x}$ & $\mathrm{x}$ \\
\hline PRO-CTCAE & & $\mathrm{x}$ & & & & & & & & $\mathrm{x}$ \\
\hline Adverce events & & $\mathrm{x}$ & $\mathrm{x}$ & $\mathrm{x}$ & $\mathrm{x}$ & $\mathrm{x}$ & $\mathrm{x}$ & $\mathrm{x}$ & $\mathrm{x}$ & $\mathrm{x}$ \\
\hline $\begin{array}{c}\text { Patient related } \\
\text { factor survey }\end{array}$ & & & & & & & & & & $\mathrm{x}$ \\
\hline Patient satisfaction & & & & & & & & & & $\mathrm{x}$ \\
\hline
\end{tabular}

Figure 2 The schedule of enrolment, interventions and assessments. 
the patients after the assessment period (0-168hours). Figure 2 provides details of the schedule of enrolment, interventions and assessments.

\section{Study design and statistical methods}

The hypothesis of this study is that the CR rate for $5 \mathrm{mg}$ OLZ plus GRA, NK RA (aprepitant or fosaprepitant) and DEX for AUC $\geq 4 \mathrm{mg} / \mathrm{mL} / \mathrm{min}$ CBDCA combination therapy is significantly higher than the CR rate for standard antiemetic triplet therapy.

Two previous randomised controlled trials reported a CR rate around $60 \% \cdot{ }^{56} \mathrm{An}$ improvement of the treatment effect has to be $>10 \%$ to amend the guideline of the MASCC/ESMO 2016. ${ }^{3}$ Based on research by Navari et al, ${ }^{14}$ improvement around $15 \%$ in the CR rate is expected. Considering the safety of OLZ, an improvement of more than $15 \%$ would be clinically meaningful.

Assuming a null hypothesis of the CR rate $\leq 60 \%$ and an alternative hypothesis of $75 \%$, a minimum of 53 patients is required to achieve a one-sided type I error of $0.1 \%$ and $80 \%$ power based on the exact binomial distribution. The target sample size is set at 60 as some patient dropout is expected.

\section{Patient and public involvement}

Patients and/or public were not involved in the design of this study.

\section{ETHICS AND DISSEMINATION}

Data will be presented at international conferences and published in peer-reviewed journals.

\section{Participating institutions}

Gifu University Hospital, Shizuoka Cancer Center, Gunma Prefectural Cancer Center.

\section{Author affiliations}

${ }^{1}$ Department of Pharmacy, Gifu University Hospital, Gifu, Japan

${ }^{2}$ Laboratory of Pharmacy Practice and Social Science, Gifu Pharmaceutical University, Gifu, Japan

${ }^{3}$ Cancer Biostatistics Laboratory, National Hospital Organization Kyusyu Cancer Center, Fukuoka, Japan

${ }^{4}$ Division of Gynecology, Shizuoka Cancer Center, Shizuoka, Japan

${ }^{5}$ Department of Obstetrics and Gynecology, Gifu University Graduate School of Medicine, Gifu, Japan

${ }^{6}$ Division of Pharmacy, Gunma Prefectural Cancer Center, Gunma, Japan

${ }^{7}$ Department of Pharmacy, Shizuoka Cancer Center, Shizuoka, Japan

\section{Contributors HI, MS, MA, YH, YF, KM made a significant contribution to the} conception and design of the study protocol. MS provided statistical expertise. The protocol was written by HI, MS, MA, MS, YN, and was critically reviewed by AS, and KM. HI, RM, and YH drafted the manuscript. All the authors read and approved the final paper.

Funding The authors have not declared a specific grant for this research from any funding agency in the public, commercial or not-for-profit sectors.

Competing interests None declared.

Patient consent for publication Obtained.

Ethics approval The study protocol was approved by the institutional review board at each of the participating centres.

Provenance and peer review Not commissioned; externally peer reviewed.
Open access This is an open access article distributed in accordance with the Creative Commons Attribution Non Commercial (CC BY-NC 4.0) license, which permits others to distribute, remix, adapt, build upon this work non-commercially, and license their derivative works on different terms, provided the original work is properly cited, appropriate credit is given, any changes made indicated, and the use is non-commercial. See: http://creativecommons.org/licenses/by-nc/4.0/.

\section{REFERENCES}

1. de Boer-Dennert $\mathrm{M}$, de Wit R, Schmitz $\mathrm{PI}$, et al. Patient perceptions of the side-effects of chemotherapy: the influence of $5 \mathrm{HT} 3$ antagonists. Br J Cancer 1997;76:1055-61.

2. Hesketh PJ, Kris MG, Basch E, et al. Antiemetics: American Society of Clinical Oncology Clinical Practice Guideline Update. J Clin Oncol 2017;35:3240-61.

3. Roila F, Molassiotis A, Herrstedt J, et al. 2016 MASCC and ESMO guideline update for the prevention of chemotherapyand radiotherapy-induced nausea and vomiting and of nausea and vomiting in advanced cancer patients. Ann Oncol 2016;27:v119-33.

4. NCCN clinical practice guidelines in oncology: Antiemesis Version 22017 https://www.nccn.org/professionals/physician_gls/pdf/ antiemesis.pdf

5. Tanioka M, Kitao A, Matsumoto K, et al. A randomised, placebocontrolled, double-blind study of aprepitant in nondrinking women younger than 70 years receiving moderately emetogenic chemotherapy. Br J Cancer 2013;109:859-65.

6. Yahata $\mathrm{H}$, Kobayashi $\mathrm{H}$, Sonoda K, et al. Efficacy of aprepitant for the prevention of chemotherapy-induced nausea and vomiting with a moderately emetogenic chemotherapy regimen: a multicenter, placebo-controlled, double-blind, randomized study in patients with gynecologic cancer receiving paclitaxel and carboplatin. Int J Clin Oncol 2016;21:491-7.

7. Ito $\mathrm{Y}$, Karayama M, Inui $\mathrm{N}$, et al. Aprepitant in patients with advanced non-small-cell lung cancer receiving carboplatin-based chemotherapy. Lung Cancer 2014;84:259-64.

8. Kusagaya $\mathrm{H}$, Inui $\mathrm{N}$, Karayama $\mathrm{M}$, et al. Evaluation of palonosetron and dexamethasone with or without aprepitant to prevent carboplatin-induced nausea and vomiting in patients with advanced non-small-cell lung cancer. Lung Cancer 2015;90:410-6.

9. Hesketh PJ, Aapro M, Street JC, et al. Evaluation of risk factors predictive of nausea and vomiting with current standard-of-care antiemetic treatment: analysis of two phase III trials of aprepitant in patients receiving cisplatin-based chemotherapy. Support Care Cancer 2010;18:1171-7.

10. Warr DG, Street JC, Carides AD. Evaluation of risk factors predictive of nausea and vomiting with current standard-of-care antiemetic treatment: analysis of phase 3 trial of aprepitant in patients receiving adriamycin-cyclophosphamide-based chemotherapy. Support Care Cancer 2011;19:807-13.

11. Hilarius DL, Kloeg PH, van der Wall E, et al. Chemotherapy-induced nausea and vomiting in daily clinical practice: a community hospitalbased study. Support Care Cancer 2012;20:107-17.

12. Sekine I, Segawa $Y$, Kubota K, et al. Risk factors of chemotherapyinduced nausea and vomiting: index for personalized antiemetic prophylaxis. Cancer Sci 2013;104:711-7.

13. Brafford MV, Glode A. Olanzapine: an antiemetic option for chemotherapy-induced nausea and vomiting. J Adv Pract Oncol 2014;5:24-9.

14. Navari RM, Qin R, Ruddy KJ, et al. Olanzapine for the Prevention of Chemotherapy-Induced Nausea and Vomiting. N Engl J Med 2016;375:134-42.

15. Castberg I, Westin AA, Skogvoll E, et al. Effects of age and gender on the serum levels of clozapine, olanzapine, risperidone, and quetiapine. Acta Psychiatr Scand 2017;136:455-64.

16. Abe M, Hirashima $Y$, Kasamatsu $Y$, et al. Efficacy and safety of olanzapine combined with aprepitant, palonosetron, and dexamethasone for preventing nausea and vomiting induced by cisplatin-based chemotherapy in gynecological cancer: KCOG-G1301 phase II trial. Support Care Cancer 2016;24:675-82.

17. Nakashima K, Murakami H, Yokoyama K, et al. A Phase Il study of palonosetron, aprepitant, dexamethasone and olanzapine for the prevention of cisplatin-based chemotherapy-induced nausea and vomiting in patients with thoracic malignancy. Jpn J Clin Oncol 2017:47:840-3.

18. Yanai T, Iwasa $\mathrm{S}$, Hashimoto $\mathrm{H}$, et al. A double-blind randomized phase ll dose-finding study of olanzapine $10 \mathrm{mg}$ or $5 \mathrm{mg}$ for the prophylaxis of emesis induced by highly emetogenic cisplatin-based chemotherapy. Int J Clin Oncol 2018;23:382-8. 